\title{
A PRODUÇÃO DO OURO EM PARACATU / MG - BRASIL: RISCOS PARA A SAÚDE E BEM ESTAR DA POPULAÇÃO
}

\section{THE GOLD PRODUCTION IN PARACATU / MG - BRAZIL: RISKS TO HEALTH AND THE POPULATION'S WELFARE}

\author{
Joana D'Arc Vieira Couto Astolphi \\ Universidade Federal de Uberlândia (UFU), Uberlândia, Brasil \\ jastolphi@yahoo.com.br \\ Érico Soriano \\ Universidade do Porto (UP), Porto, Portugal \\ ericogeo@gmail.com \\ Vicente de Paulo da Silva \\ Universidade Federal de Uberlândia (UFU), Uberlândia, Brasil \\ vicente.paulo@ufu.br
}

\begin{abstract}
RESUMO
Paracatu é uma cidade histórica brasileira do Ciclo da Mineração no país, localizada no noroeste do estado de Minas Gerais. Atualmente é conhecida devido a sua grande produção de ouro, através da exploração da maior mina a céu aberto do mundo, operada pela empresa Kinross Brasil Mineração. Esta grandiosidade também se observa nos impactos socioambientais negativos gerados pela atividade produtiva. Buscou-se identificar a relação entre os impactos socioambientais produzidos pela mineração industrial, com os problemas de saúde e de bem-estar identificados na população. Desta forma, analisou-se o processo de adoecimento dos moradores, a partir da base de dados SIH/SUS do DATASUS, assim como a literatura e documentos acerca dos riscos da produção minerária sobre a saúde e o bem-estar dos moradores e a realização de entrevistas semiestruturadas com moradores que residem em bairros contíguos à área de lavra da mineradora. Foi possível constatar que as condições de saúde e o processo de adoecimento de parte da população podem revelar uma possível relação com as práticas da mineração.
\end{abstract}

Palavras-chave: Riscos. Mineradora. Doença. Ouro.

\begin{abstract}
Paracatu is a historical Brazilian mining town, located in the northwest of the state of Minas Gerais. It is currently known for its large gold production through the exploration of the largest open pit mine in the world, operated by the company Kinross Brazil Mining. This grandeur is also observed in the negative socioenvironmental impacts generated by the productive activity. We sought to identify the relationship between the socio-environmental impacts produced by industrial mining, with the health and well-being problems identified in the population. Thus, we analyzed the process of illness of residents, from the DATASUS $\mathrm{SIH} / \mathrm{SUS}$ database, as well as the literature and documentary about the risks of mining production on the health and welfare of residents and semi-structured interviews with residents living in neighboring neighborhoods of the productive activity of the mining company. It was found that the health conditions and the process of illness of part of the population are closely related to mining practices.
\end{abstract}

Keywords: Risks. Mining company. Disease. Gold.

\section{INTRODUÇÃO}

A mineração sempre foi uma das principais atividades econômicas do Brasil, o qual, atualmente, é considerado um dos maiores produtores de minérios no mundo (BRASIL, 2018a). A referida atividade representa um dos setores mais importantes da economia brasileira, com uma exportação da ordem de US\$ 29,9 bilhões no ano de 2018 , com destaque para a produção de minério de ferro, que

Recebido em: 15/09/2020

Aceito para publicação em: 08/02/2021. 
concentra aproximadamente $68 \%$ das exportações (IBRAM, 2018). Considerando-se a produção do ouro, o valor das exportações foi entorno de US\$2.814.408.337. De acordo com a United States Geological Survey, o Brasil produziu $81.000 .000 \mathrm{~kg}$ de ouro no ano de 2018.

Paracatu, conhecida como a cidade do ouro, é um município localizado na região noroeste do estado de Minas Gerais, caracterizado historicamente pela presença de minerais preciosos como o ouro. Essa condição também faz com que o município, bem como a cidade e seus moradores, conviva com a presença da atividade mineradora, em especial a exploração do ouro, feita pela Kinross Brasil Mineração, subsidiária da empresa Kinross Gold Corporation. A mina, localizada a uma proximidade muito estreita com a área urbana do município, é considerada a maior mina de ouro a céu aberto do mundo. Esse fato pode gerar efeitos nocivos à saúde e ao bem-estar de moradores e de trabalhadores da empresa.

Segundo Barros (2017), a história do desenvolvimento social e econômico do município de Paracatu remonta ao chamado ciclo da mineração, ou ciclo do ouro no Brasil, principalmente com a exploração do território de Minas Gerais, onde a extração e a exportação deste minério determinaram a dinâmica econômica da colônia. Neste contexto, destaca-se o Morro do Ouro em Paracatu, que foi o marco do povoamento da região, como pode ser visualizado na figura 1.

Figura 1 - Localização da Mina Morro do Ouro.

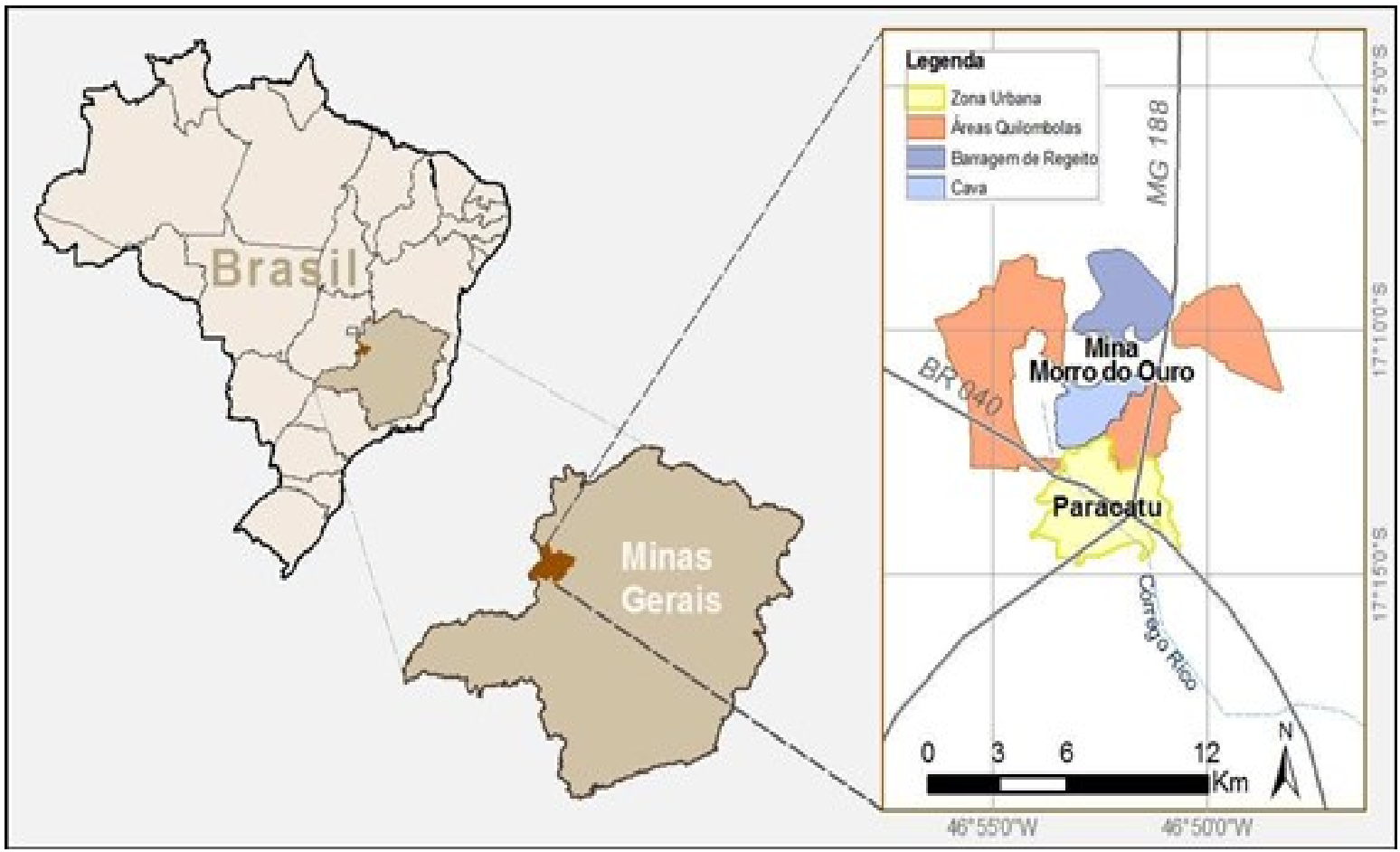

Fonte: Santos (2012).

A produção minerária brasileira e a sua exploração predatória, são responsáveis pela geração de riscos, em níveis diferenciados, para a saúde e bem-estar da população, principalmente quando essa exploração é feita em larga escala. No caso de Paracatu, a vulnerabilidade é bem maior nos grupos populacionais que residem em bairros contíguos à empresa, como pode ser visualizado nas Figuras 2 e 3. Neste sentido, este estudo teve como objetivo analisar a possível relação entre os impactos produzidos pela atividade produtiva de uma empresa mineradora, com prevalência de determinadas doenças/sintomatologia na região, assim como a redução no bem-estar dos moradores que residem próximos da mesma. 
Figura 2 - Proximidade da atividade minerária com a cidade de Paracatu

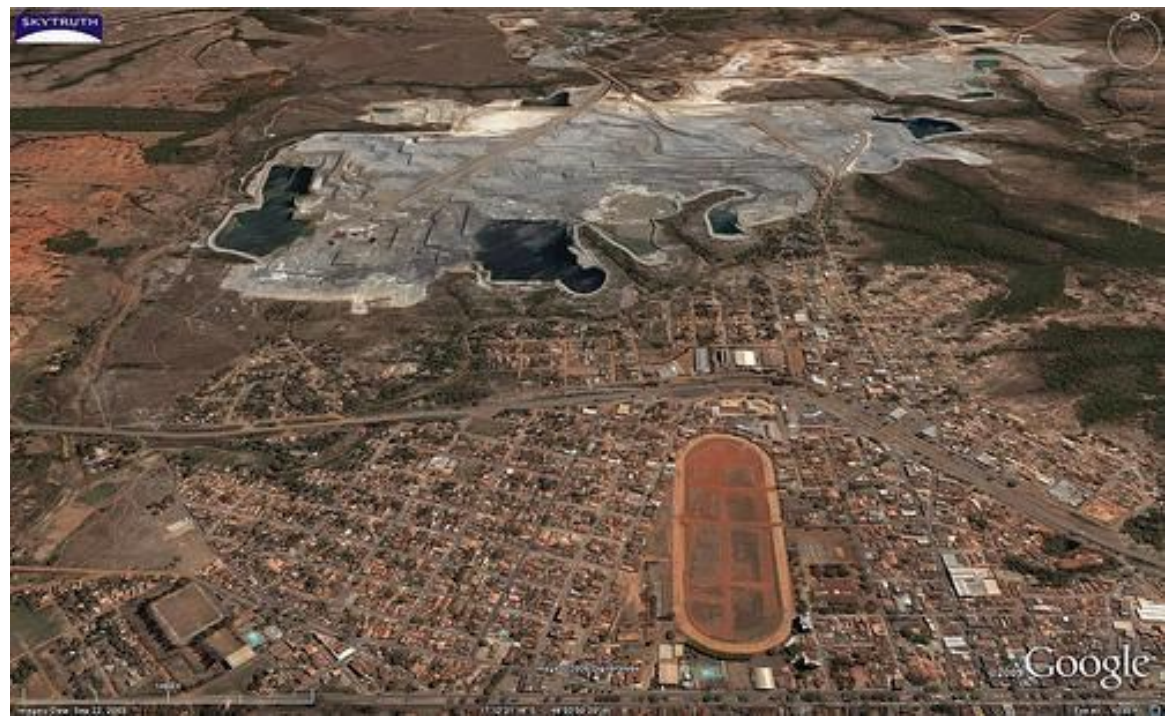

Fonte: Flickr/SkyTruth www.ecodebate.com.br (2013).

Figura 3 - Limite entre a área urbana de Paracatu e a Mina Morro do Ouro.

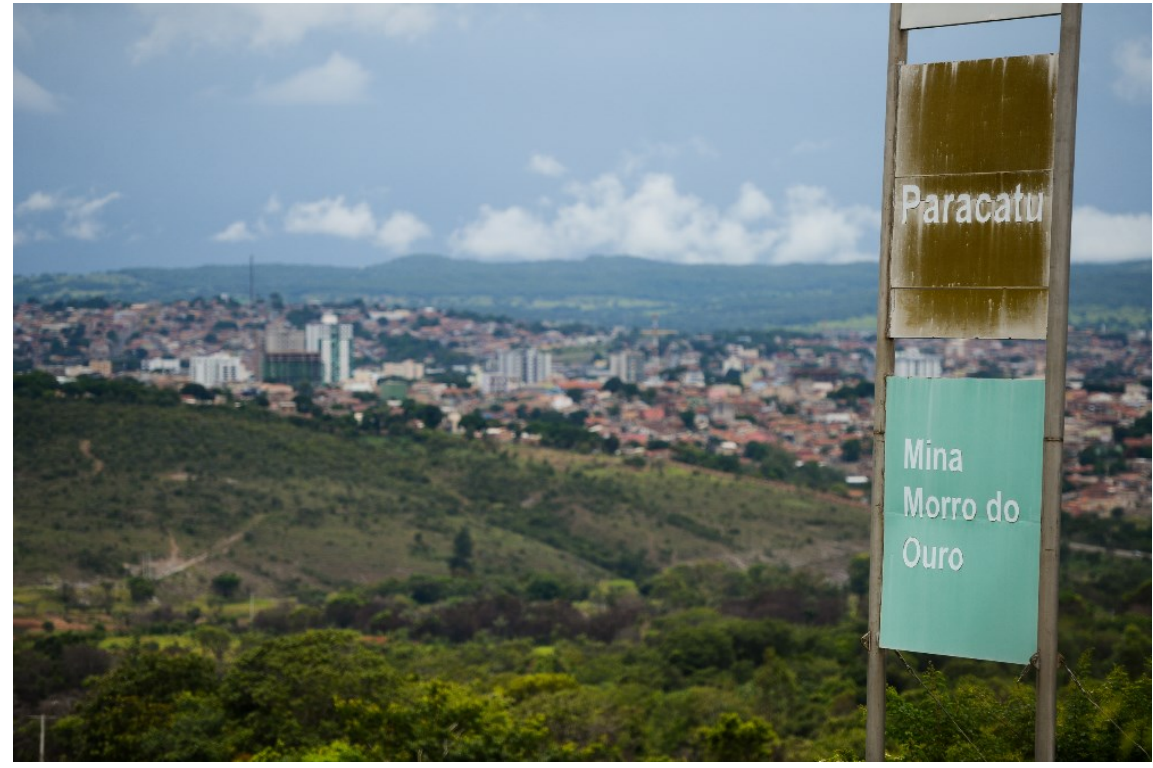

Fonte: Cruz/Agência Brasil (2015).

O Morro do Ouro figura como a maior mina de ouro no Brasil, sendo responsável por $22 \%$ da produção nacional do minério (KINROSS, 2020). De acordo com Amado (2019) o grupo canadense Kinross Gold Corporation atua em pesquisa e desenvolvimento mineral, mineração, beneficiamento e comercialização de ouro. A atuação da empresa também se faz presente no Chile, Estados Unidos, Canadá, Gana, Mauritânia e Rússia. A mina Morro do Ouro tem vida útil esperada até 2032 e começou a ser explorada em 1987.

Sabe-se que empreendimentos dessa magnitude podem resultar em uma série de impactos e consequências negativas para a população, tais como, apropriação e degradação do solo; alteração na fisionomia da paisagem; excesso de ruídos e vibrações, além de uma grande quantidade de 
material particulado em suspensão, em função da detonação de rochas. Ainda é possível a ocorrência de poluição das águas superficiais e subterrâneas; resíduos do capeamento e estéreis presentes nas atividades de extração e beneficiamento do ouro, principalmente pelo caráter de céu aberto.

Os trabalhos de campo realizados em Paracatu, com vistas à realização dessa pesquisa, revelaram que há muitas evidências de riscos produzidos pela mineração no tecido urbano, os quais podem ser perceptíveis na fisionomia da paisagem. Foi possível registrar imagens desoladoras as quais permitem inferir que são semelhantes às "paisagens do medo", conforme denominação de Tuan (2005). Observa-se a apreensão de parte da população por residir próximos a duas grandes barragens de rejeitos de minérios, principalmente num período em que no Brasil se vive um cenário de rompimentos de barragens de rejeitos recentes no país, como ilustram os casos de Mariana-MG (2015) e Brumadinho, também em Minas Gerais (2019).

A mineração industrial em Paracatu é uma das poucas operações de extração mineral em atividade no mundo realizada em área densamente povoada, sendo até mesmo difícil estabelecer uma linha divisória entre o tecido urbano e as áreas de lavra de minério (CASTILHOS et. al, 2020), como mostrado na figura 2. Como dito anteriormente, a atividade consiste numa exploração a céu aberto e isso permite a liberação de grande quantidade de material particulado para a atmosfera e o minério extraído é originalmente de rochas ricas em arsenopirita, mineral que possui alto teor de arsênio (BARROS, 2017). A mineração do ouro representa uma importante fonte antrópica de poluição de Arsênio (GONÇALVES, 2011; CRAW AND BOWELL, 2014; VELOSO et al. 2019). Ademais, resulta na produção de grandes volumes de rejeitos (mais de 55 milhões de toneladas em 2013), e na liberação de volumes significativos de poeira e partículas em suspensão (BARROS, 2017). Aliado ao fato de que possui um dos menores teores de ouro do mundo, com teores médios de 0,5 grama por tonelada de minério, a movimentação de rocha e terra na mina de Paracatu é gigantesca (BARROS, 2017).

\section{CONTAMINAÇÃO AMBIENTAL E RISCOS PARA A SAÚDE DA POPULAÇÃO}

A exploração de ouro tem gerado inúmeras preocupações na população de Paracatu com relação às condições de saúde ambiental. Em um contexto de incertezas e falta de informação confiável, associado às evidências na transformação dos solos, ar e água, às sensações de mal-estar e doenças recorrentes, a possibilidade de contaminação por substâncias tóxicas tornou-se um temor entre os moradores, remetido aos altos índices de câncer na cidade (BARROS, 2017).

Uma das principais ameaças refere-se à contaminação por arsênio, que é um metal bastante presente nas formações rochosas da região e considerado cancerígeno. $O$ arsênio e seus compostos são reconhecidos pela Agência Internacional de Pesquisa do Câncer e pela Agência de Proteção dos Estados Unidos como substâncias extremamente tóxicas e cancerígenas (BIDONE et al., 2018). A explosão das rochas e retirada de toneladas de terra para extração do ouro cria o problema da liberação do metal, antes preso nas rochas. Em outra etapa, o tratamento dos fragmentos de rocha com produtos químicos libera mais arsênio que são armazenados na barragem (SANTOS, 2012). Mello e Roy (2006) constataram que os solos na área de mineração de ouro em Paracatu apresentam concentrações de arsênio superiores à média da região.

Neste sentido, dentre os impactos socioambientais decorrentes da mineração industrial em Paracatu, serão contemplados neste estudo os riscos ao bem-estar e a saúde da população, em especial, prevalência de determinadas doenças/sintomatologia de moradores dos bairros contíguos à área de lavra do complexo minerário.

Conforme Castilhos et. al (2020), as amostras recolhidas em cerca de 1.000 moradores dos bairros atendidos pelos Postos de Saúde da Família (PSF), Amoreiras e Paracatuzinho, com mais de 40 anos de idade e residentes na cidade de Paracatu há pelo menos 20 anos apresentaram baixos teores de arsênio em urina. O mesmo estudo ainda revela que as águas de abastecimento doméstico da cidade também mostraram baixos teores de arsênio, indicando que não estão contaminadas. Quanto às poeiras respiráveis, de acordo com os referidos autores, estas revelaram arsênio dentro da faixa encontrada em outras áreas urbanas em vários locais do mundo. Acrescenta que, os teores de arsênio em águas superficiais e solos se mostraram, via de regra, acima do estipulado pela legislação brasileira para consumo humano, mas abaixo dos teores máximos estipulados pela mesma legislação para uso em dessedentação animal e irrigação (CASTILHOS et. al, 2020).

Outros trabalhos apontam para os riscos relativos ao cianeto presente no processo da mineração

DOI: http://dx.doi.org/10.14393/Hygeia17057324 $\quad$ Hygeia $\quad$ v.17 $\quad$ p. $55-70, \quad 2021$ página 58


industrial. Santos e Araújo (2010), advertem que outra preocupação da população refere-se ao uso do cianeto no processo produtivo e seu descarte, uma vez que, quando em contato com determinados ácidos, ele libera um gás tóxico que, se ingerido ou inalado, pode ser fatal. $O$ lançamento de rejeitos incompletamente tratados em tanques específicos, contendo cianeto residual e compostos intermediários tóxicos, seria risco elevado de contaminação ambiental (SANTOS e ARAÚJO, 2010). No relatório (Rio Tinto Brasil, 2003, apud Santos, 2012), os autores enfatizam que pode-se observar que entre 2001 e 2003, a quantidade de cianeto na poeira fugitiva da mina passou de $0,7 \mathrm{~kg} /$ ano para $2,8 \mathrm{~kg} / \mathrm{ano}$, tendo, portanto, quadruplicado.

Este risco se amplia com a possibilidade de aumento da produção de ouro pela empresa. De acordo com dados da empresa, a produção entre janeiro e setembro de 2018 apresentou um aumento de $28 \%$ comparando-se com o mesmo período do ano de 2017, aumentando de 293,9 para 375,4 mil onças de ouro. Ou seja, uma quantidade maior de arsênio em suspensão no município, assim como a utilização de mais cianeto e a crescente deposição de rejeitos de minérios nos reservatórios da empresa.

A despeito do monitoramento realizado pela mineradora em relação ao cianeto residual existem outros riscos advindos no caso da possibilidade de rompimento das barragens. Barros (2017) argumenta que a empresa faz o monitoramento do cianeto residual e da sua degradação no lago de rejeitos e afirma que as concentrações têm ficado abaixo das normas internacionais de segurança. Entretanto, uma das suas preocupações é com o rompimento da barragem e o possível vazamento do material tóxico dos tanques por meio de possíveis trincas e fraturas das rochas que se encontram abaixo da camada impermeável e a possibilidade de atingir o lençol freático.

Para efeito de comparação, o rompimento da barragem em Brumadinho liberou cerca de 12 milhões de metros cúbicos de rejeitos. De acordo com a Kinross, a empresa, em Paracatu, possui duas estruturas: a barragem Santo Antônio e a barragem Eustáquio. A primeira foi construída em 1987 e possui 483 milhões de $\mathrm{m}^{3}$ de capacidade, sendo que 399 milhões de $\mathrm{m}^{3}$ desse total são utilizados. Já a barragem Eustáquio, está em operação desde 2010 e possui 750 milhões de $\mathrm{m}^{3}$ de capacidade, sendo que 143 milhões de $\mathrm{m}^{3}$ deste total são utilizados.

\section{POPULAÇÃO LOCAL E A EXPLORAÇÃO DO OURO EM PARACATU}

As instalações e as expansões promovidas pelo empreendimento minerário, implicaram diretamente no meio social e no modo de vida da população local, em especial, daquela cujos antepassados já residiam nas áreas de interesse da empresa mineradora, antes de sua instalação. Martins (2010) alega que os descendentes dos escravos, após abolição da escravatura, descendentes dos homens libertos, que trabalharam no Córrego Rico e no Morro do Ouro, venderam suas terras e se mudaram para a periferia da cidade.

A comunidade Família dos Amaros (remanescente quilombola, constituída por descendentes de africanos escravizados no Brasil) está a jusante do eixo da Barragem do Córrego Eustáquio, conforme se vê na fig. 3. A mina, na área de concessão de lavra, fica entre dois quilombos como apresentada na fig. 5. De um lado, a extinta comunidade do Machadinho, que deu lugar à nova represa, e, do outro, São Domingos, que ainda mantém parte das tradições dos primeiros escravos que chegaram à cidade (MARTINS, 2010).

A figura 4, ilustra as sobreposições territoriais de áreas de concessão mineral da Kinross, com atividade produtiva e a zona urbana do município abrangendo áreas remanescentes quilombolas, que desencadeou relações sociais conflituosas, focadas no meio ambiente e no território (SANTOS, 2012). Com isso observa-se nítida apropriação do espaço pela empresa mineradora e a consequente destruição de territórios, além do retraimento de comunidades tradicionais que deram lugar às áreas de operação da empresa e a todos os seus riscos associados. 
Figura 4 - Paracatu (MG): periferia urbana, áreas de mineração e territórios quilombolas.

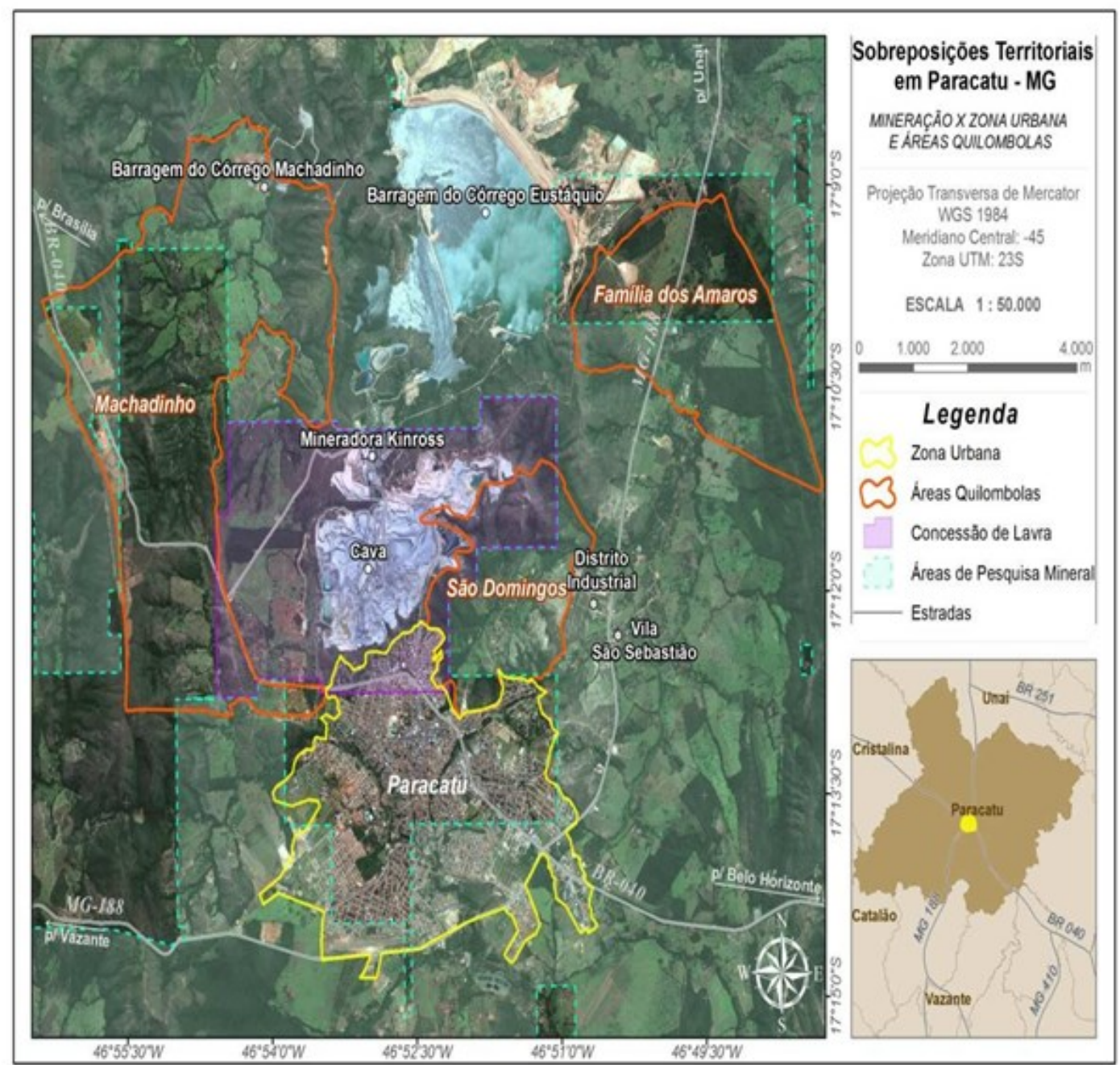

Fonte: Santos (2012).

A operação de empreendimento minerário implicou em alterações profundas no território em relação ao meio ambiente e modos de vida da população, bem como, na exposição de moradores, trazendo à tona dimensões múltiplas de vulnerabilidades presentes no seu cotidiano. A vulnerabilidade neste estudo, com base na avaliação dos diferentes riscos, pode ser definida como a somatória entre os riscos existentes em determinado local, com o grau de exposição dos grupos populacionais que residem neste local (CUTTER, 1994; 1996). Ainda de acordo com a autora supra:

[...] vulnerability is conceived as both a biophysical risk as well as a social response, but within a specific area or geographic domain. This can be geographic space, where vulnerable people and places are located, or social space, who in those places are most vulnerable (CUTTER, 1996, p.533).

Em conformidade com Veyret (2015, p. 39) a vulnerabilidade carrega uma noção complexa e que se "mede pela estimativa dos danos potenciais que podem afetar um alvo, tal como o patrimônio construído ou a população (...) pode ser compartilhada por um grupo social, ela é, então, função, em grande medida, da distribuição da população em torno do local de risco". A vulnerabilidade é multicausal e envolve uma gama de fatores "físicos, ambientais, técnicos, econômicos, psicológicos, sociais, políticos," que não convém ser definida como "meros índices científicos ou técnicos" e ainda que, os fatores socioeconômicos em sua maioria ampliam a vulnerabilidade das populações ameaçadas (VEYRET, 2015, p. 40-41). 
Neste estudo foram considerados os moradores que vivem na periferia do núcleo urbano, em áreas limítrofes a essas atividades e que ficam submetidos à variedade de efeitos produzidos pelas práticas de exploração do bem natural, com base na percepção e na representação dos grupos populacionais em relação a sua saúde e seu nível de bem-estar.

\section{APROPRIAÇÃO DO TERRITÓRIO E A DEPENDÊNCIA ECONÔMICA}

A expansão do empreendimento da Kinross, em especial da barragem de rejeitos de mineração, significou a usurpação, por meio de estratégias diversas, de áreas dentro dos territórios das comunidades quilombolas de Machadinho, Amaros e São Domingos, localizadas no entorno do Morro do Ouro, sendo que nos dois primeiros resultou na expulsão de todas as famílias que ali residiam (BARROS, 2017). Com efeito, a apropriação do território foi perpetuada no decorrer do tempo no processo de deslocamento compulsório ao qual a população fora submetida. Para Barros (2017), a tomada e expropriação dos territórios deram-se ao longo dos anos por meio de inúmeras pressões sobre as famílias residentes nas áreas de interesse da mineradora.

A Compensação Financeira pela Exploração de Recursos Minerais (CFEM) é uma contraprestação paga à União pelo aproveitamento econômico de recursos minerais que conforme o Decreto $\mathrm{n}^{\circ} 1 /$ 1991 o CFEM incide sobre o faturamento líquido, no caso da venda do minério bruto e beneficiado, ou no custo intermediário de produção, quando o produto mineral é consumido ou transformado em um processo industrial (BRASIL, 2018b).

De acordo com o Departamento Nacional de Produção Mineral-DNPM (Brasil, 2008), em referência à distribuição dos recursos de CFEM, $12 \%$ deles destinam-se à União, 23\% repassados ao Estado de origem da extração e $65 \%$ destinados ao município onde ocorre a extração. A cota- parte da União é dividida entre o DNPM com 9,8\%; o Instituto Brasileiro do Meio Ambiente e dos Recursos Naturais Renováveis (IBAMA) com $0,2 \%$ e o Ministério da Ciência, Tecnologia e Inovação através do Fundo Nacional de Desenvolvimento Científico e Tecnológico - MCT/FNDCT com $2 \%$.

O setor mineral exerce a sua importância econômica, para além da instância federal, nos níveis estadual e municipal por meio da arrecadação e economia local. De fato, a CFEM, corresponde aos royalties pagos pelas mineradoras aos Estados e municípios.

Em 2017, o setor mineral pagou cerca de $\mathrm{R} \$ 1,8$ bilhão com a CFEM (BRASIL, 2018b). Em Paracatu, a arrecadação procedente de CFEM, ao longo dos últimos quatorze anos demonstra uma evolução positiva na maioria do período estudado, crescimento este representado na figura 5.

Figura 5 - Arrecadação CFEM destinada ao município de Paracatu em Reais -2005 a 2018.

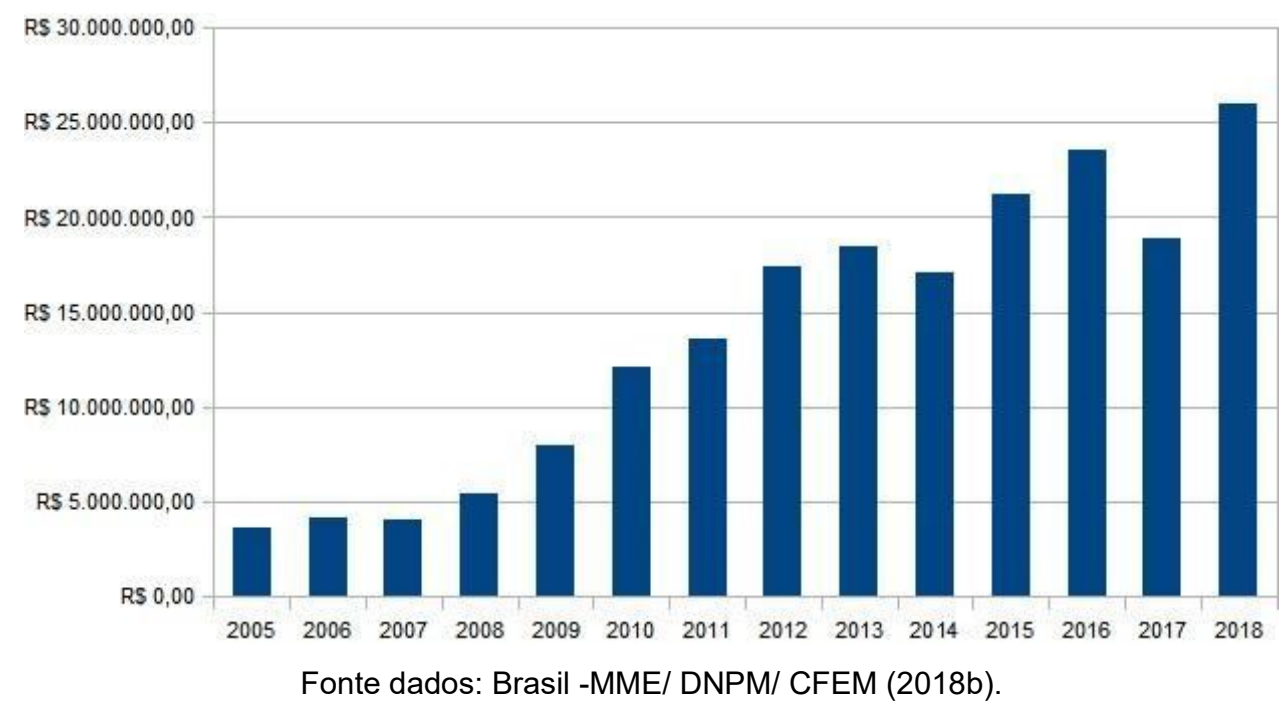

Através da figura 5, é possível verificar a importância econômica da atividade minerária no município de Paracatu. Ressalta-se que além da arrecadação do CFEM, também há os empregos diretos e 
indiretos decorrentes da presença da mineradora. Um processo que levou a uma condição de dependência muito grande. Isso significa que nos dias de hoje tanto a gestão pública municipal quanto os próprios moradores, ou os trabalhadores, não conseguem sequer imaginar que a empresa interrompa suas obras mesmo cientes dos riscos que a mineração expõe a população. A empresa criou essa suposta dependência uma vez que propaga a ideia de que parar com a exploração do ouro significa desemprego em massa e um futuro incerto ao trabalhador que tem nessa relação uma, também suposta, segurança para a sobrevivência da família.

Neste estudo, analisou-se de forma integrada as atividades da mineradora no município e os riscos para a população urbana exposta aos diversos efeitos dessa produção, bem como o nível do bemestar desses moradores, em especial dos bairros periféricos (microescala) contíguos às áreas de mineração. Os moradores dos bairros Alto da Colina e Bela Vista II, participantes da pesquisa, para a coleta de dados primários sobre o significado do território para este grupo, incluindo a visão que têm dos riscos aos quais estão submetidos, possibilitam o estudo na microescala. De acordo com Brito (2006, p.103), em relação às pesquisas geográficas em microescala, aquelas focadas em um bairro, cidade, comunidade, favela, minifúndio, rua, aldeia, dentre outras, compreende que " [...] na vida cotidiana, estão expressas e impressas todas as escalas espaciais, desde o corpo (...) até o espaço maior (sentido global). As pessoas vivem no cotidiano do corpo, do lugar, do território e do mundo". A escolha por uma escala de trabalho, no caso a microescala, definida para a coleta de dados primários com os moradores residentes nos bairros acima citados, encontra-se articulada com as escalas local (município) e global (empresa mineradora) por entender que o objeto de estudo é multiescalar.

\section{IMPACTOS SOCIOAMBIENTAIS ASSOCIADOS À ATIVIDADE MINERÁRIA EM PARACATU}

O complexo minerário da Kinross localiza-se somente a 2 quilômetros da região central da cidade (Kinross, 2018), praticamente dentro da zona urbana. A população dos bairros contíguos à área de operação da mineradora sofre com os impactos dos explosivos e ruídos cuja incidência coloca em risco as condições de moradia e, consequentemente, a saúde e bem-estar dos moradores. As detonações promovidas diariamente pela empresa podem ser ouvidas em toda a cidade e causam abalos sísmicos que atingem, em graus variados, bairros e áreas rurais próximas, principalmente a comunidade quilombola de São Domingos e os bairros Amoreiras II, Bela Vista II e Alto da Colina (BARROS, 2017).

A atividade mineradora, historicamente e com base em legislação, concentrou sua gestão de riscos em questões relacionadas à saúde e à segurança dos seus empregados, assim como nos impactos ao meio ambiente, por conta da legislação. Por outro lado, os efeitos e riscos dessa atividade em comunidades vizinhas por muito tempo não recebeu a devida atenção por parte tanto de empreendedores, quanto do próprio poder público. Embora seja uma atenção crescente nos últimos anos, ainda faltam muitos estudos sobre como esta atividade afeta as comunidades vizinhas ao empreendimento, assim como minimizar os impactos negativos que estejam causando (SINCOVICH et al., 2018).

O estudo de Barros (2017), demonstra que de acordo com os depoimentos colhidos, todos os dias, às três ou quatro horas da tarde, a empresa soa o alarme três vezes e realiza as detonações. Nesse instante, o tremor de terra gera a movimentação de objetos no interior das moradias e rachaduras nas casas. Os moradores denunciam ainda que no período noturno o barulho dos maquinários é insuportável e que os funcionários desligam as máquinas antes de realizarem as medições de monitoramento dos ruídos. Além de abalar as estruturas das suas residências, as detonações levantam uma enorme quantidade de poeira que os moradores temem ser tóxica (BARROS,2017).

$\mathrm{O}$ uso intensivo da água e a destruição das nascentes constituem impactos ambientais decorrentes da exploração mineral em larga escala. Santos (2012) assevera que estudos elaborados pelo governo estadual, por meio de um Zoneamento Ecológico-Econômico de Minas Gerais, confirmam um comprometimento da água superficial em todo o espaço territorial do município de Paracatu. Para Souza (2015) a captação das águas subterrâneas e superficiais para o sistema de irrigação da atividade agropecuária caracteriza-se por um consumo mais expressivo de água e para o sistema industrial da mineração destaca-se o comprometimento da qualidade da água por conta das substâncias químicas empregadas.

Em relação à destruição das nascentes, conforme Souza (2014), inúmeras nascentes e córregos simplesmente desapareceram em decorrência da mineração, como a nascente do Córrego Rico, no 
Morro do Ouro, que foi transformada numa imensa cratera ácida e morta; os córregos Bandeirinha, Assassino e Criminoso, com suas respectivas cachoeiras, deram lugar ao tanque de contenção para o abastecimento do processo industrial; os córregos Boa Vista, Eustáquio, Senhor Lio, Senhor Marcelino, Elizeu Araújo e Sales foram destruídos com o soterramento do vale do Machadinho para a construção da nova barragem de rejeitos; o córrego São Domingos, represado pela mineradora, possui um filete de água, e o córrego Santo Antônio por sua vez já desapareceu.

\section{MATERIAIS E MÉTODOS}

Este estudo buscou analisar os impactos negativos da produção mineral em larga escala sobre grupos populacionais expostos aos efeitos dessa exploração, com base na prevalência de determinadas doenças/sintomatologia na região. Tomou-se como referência o caso da Kinross em Paracatu e, como sujeitos da pesquisa, os moradores que residem nos bairros contíguos à atividade produtiva da empresa. Desta forma, tendo por subsídio a base de dados do Sistema de Informação Hospitalar (SIH/SUS) do Departamento de Informática do Sistema único de Saúde do Brasil (DATASUS), analisou-se a condição de saúde da população.

Neste sentido, após a análise da literatura e documental sobre os riscos e os impactos da mineração sobre a saúde, foram analisadas as entrevistas produzidas em campo, através de uma amostragem populacional de residentes dos dois bairros contíguos à atividade produtiva da Kinross.

A distribuição dos grupos entrevistados foi baseada na amostragem "não probabilística" e especificamente do tipo "por acessibilidade ou conveniência" Gil (1999) prevista para o levantamento de dados de fonte primária, mencionada na metodologia.

Em alusão ao grupo de moradores dos bairros Alto da Colina e Bela Vista II, os critérios para composição da amostragem foram grupo de homens e mulheres, na faixa etária de 18 anos ou mais de idade, com a aplicação do instrumento Roteiro 1 para entrevista semiestruturada. A observância do número mínimo programado de $5 \%$ da população dos dois bairros num total de 44 pessoas e máximo programado de $10 \%$ da população num total de 90 pessoas foi cumprida e extrapolada em números absolutos de mais 5 pessoas no total geral de 95 pessoas entrevistadas dos respectivos bairros.

O instrumento utilizado foi um roteiro de entrevista com a questão norteadora: avaliação da saúde do próprio indivíduo e de sua família e os problemas de saúde enfrentados, associados aos riscos advindos da proximidade com as atividades do complexo minerário.

Tuan (1983) contribui ao tratar da qualidade ambiental, a partir da compreensão do que as pessoas sentem sobre espaço e lugar, considerando as diferentes maneiras de experienciar (sensório-motora, tátil, visual, conceitual) e interpretar o espaço e lugar como imagens de sentimentos complexos, com a possibilidade de articular sutis experiências humanas.

\section{RESULTADOS E DISCUSSÃO}

Neste estudo a percepção dos riscos socioambientais advindos da presença do empreendimento minerário, implicará no entendimento de um tema que interpela o ser humano "o medo", tratado na obra de Tuan (2005), a qual explora o medo na criança, o medo na sociedade medieval, o medo de doença, o medo da natureza, o medo no campo, o medo nas cidades, os medos no passado e no presente, seus respectivos significados e as mais variadas faces que revelam um mundo em que as mudanças implicam num caráter transitório de tudo que envolve as pessoas colaborando para um contínuo sentimento de ansiedade.

Neste sentido, na sequência, são apresentadas algumas falas dos moradores dos bairros Bela Vista II e Alto da Colina entrevistados neste estudo, na qual avaliam seu bem-estar e sua condição de saúde enfrentados.

Ao serem questionados sobre tipos de enfermidades que já os afligiram, considerando o tempo em que estão expostos a fatores ligados à atividade minerária, destacam-se as afirmações acerca das condições respiratórias na área de estudo:

- $\quad$ "Problema respiratório e no pulmão. Cansaço e tontura com frequência. Doença como câncer" (Entrevistado 12);

- $\quad$ "Alergia, gripe e resfriado por causa da poeira" (Entrevistado 17); 
- $\quad$ "Problemas com resfriados e alergias pela poeira do ar" (Entrevistado 25);

- "Movimentos das pernas bem limitados, problemas respiratórios pela poluição do ar" (Entrevistado 28);

- "Doenças respiratórias como rinite, resfriado e gripe, provocadas pelo volume de poeira" (Entrevistado 89);

- $\quad$ "Em algum momento todos já adoeceram. Rinite e outros problemas respiratórios" (Entrevistado 90).

Com base nas falas dos entrevistados, a poeira resultante da explotação do ouro representa um grande desconforto para os bairros analisados. Porém, em campo, foi possível constatar que esta situação ocorre em toda área urbana do município de Paracatu. Este particulado, associado ao processo de estiagem que caracteriza o outono e inverno da região, guardam as condições para o surgimento de doenças respiratórias, como indicado pelos entrevistados.

Uma parcela expressiva dos entrevistados também fez uma relação entre o particulado residual e as neoplasias:

\footnotetext{
- Câncer, bronquite, rinite alérgica, resfriado e gripe" (Entrevistado 19);

- "Aumento de casos de câncer e das doenças respiratórias como sinusite, bronquite e resfriado, além das doenças de pele" (Entrevistado 24).
}

Também de acordo com a percepção dos entrevistados, a incidência de problemas associados à hipertensão e cardiopatias também são um resultado direto da atividade produtiva:

- $\quad$ "Desde que mudamos ninguém mais teve saúde. A mãe está internada pelo coração e eu já fiz duas cirurgias. Temos hipertensão" (Entrevistado 49);

- "Problemas respiratórios por causa da poeira. Eu sou hipertenso" (Entrevistado 52);

- "Tireoide, coração, vista, hipertensão, etc. Minha saúde não vale nada" (Entrevistado 59);

- "Cardiopatia, hipertensão, gastrite e bactéria no estômago, artrite e artrose" (Entrevistado 70);

- "Hipertensão, asma, gripe, alergia, irritação da pele" (Entrevistado 71);

- $\quad$ "Alergias, gripe, resfriado, bronquite, asma, câncer aumentado devido às substâncias usadas na mineração do ouro" (Entrevistado 72);

- "Sou cardiopata e hipertenso, tenho marcapasso. Uso medicamento controlado para a ansiedade" (Entrevistado 87);

- "Na minha casa eu tenho problemas de pressão alta, de visão, dor de cabeça e já tive AVC e o meu marido está doente com nódulos na virilha, a nossa saúde não está valendo de nada, os esteios da casa estão vivendo com a graça de Deus" (Entrevistado 94).

O levantamento de dados secundários, especificamente as internações pelo Sistema Único de Saúde (SUS), por local de procedência e durante uma década, subsidiou a análise da ocorrência de doenças mais comuns e respectiva incidência na população total de Paracatu.

Optou-se por utilizar o levantamento das internações por local de residência, (SIH/SUS) de 2008 a 2017 para analisar a condição de saúde e a morbidade hospitalar da totalidade do município de Paracatu num período de dez anos, conforme figura 6. O grupo de doenças que registrou a maior frequência de internação foi a de doenças do aparelho respiratório, com 5726 internações, seguida pelo grupo de doenças do aparelho circulatório com 4792 internações, em terceiro lugar as doenças do aparelho digestivo com 3.681 internações. Na sequência aparecem as doenças do aparelho geniturinário com 2.503 internações e em quinto lugar as neoplasias [tumores] com 1.546 internações.

DOI: http://dx.doi.org/10.14393/Hygeia17057324 $\quad$ Hygeia $\quad$ v.17 $\quad$ p. $55-70, \quad 2021$ página 64


Pode-se inferir sobre uma possível relação entre as doenças dos sistemas respiratório, circulatório e neoplasias e os riscos provenientes da mineração industrial. O primeiro sistema associado aos materiais particulados em suspensão no ar como a poeira tóxica; o segundo sistema com a degradação no lago de rejeitos do cianeto utilizado no tratamento do minério e o terceiro sistema pela presença de arsenopirita, um mineral de arsênio, que é liberado durante o processo de escavação das rochas e a exposição longitudinal. Observa-se que os achados referentes à evolução das internações por grupo de doenças vistos na figura 6 , revelaram ser semelhantes aos relatados dos participantes, moradores dos bairros pesquisados, quanto aos distúrbios de saúde presentes, como mostra a Tabela I. Neste sentido, as doenças possíveis de associação aos efeitos negativos da mineração em larga escala, foram comumente encontradas na coleta de dados secundários e primários.

Figura 6 - Internação hospitalar de moradores residentes em Paracatu (MG) no período 2008-2017

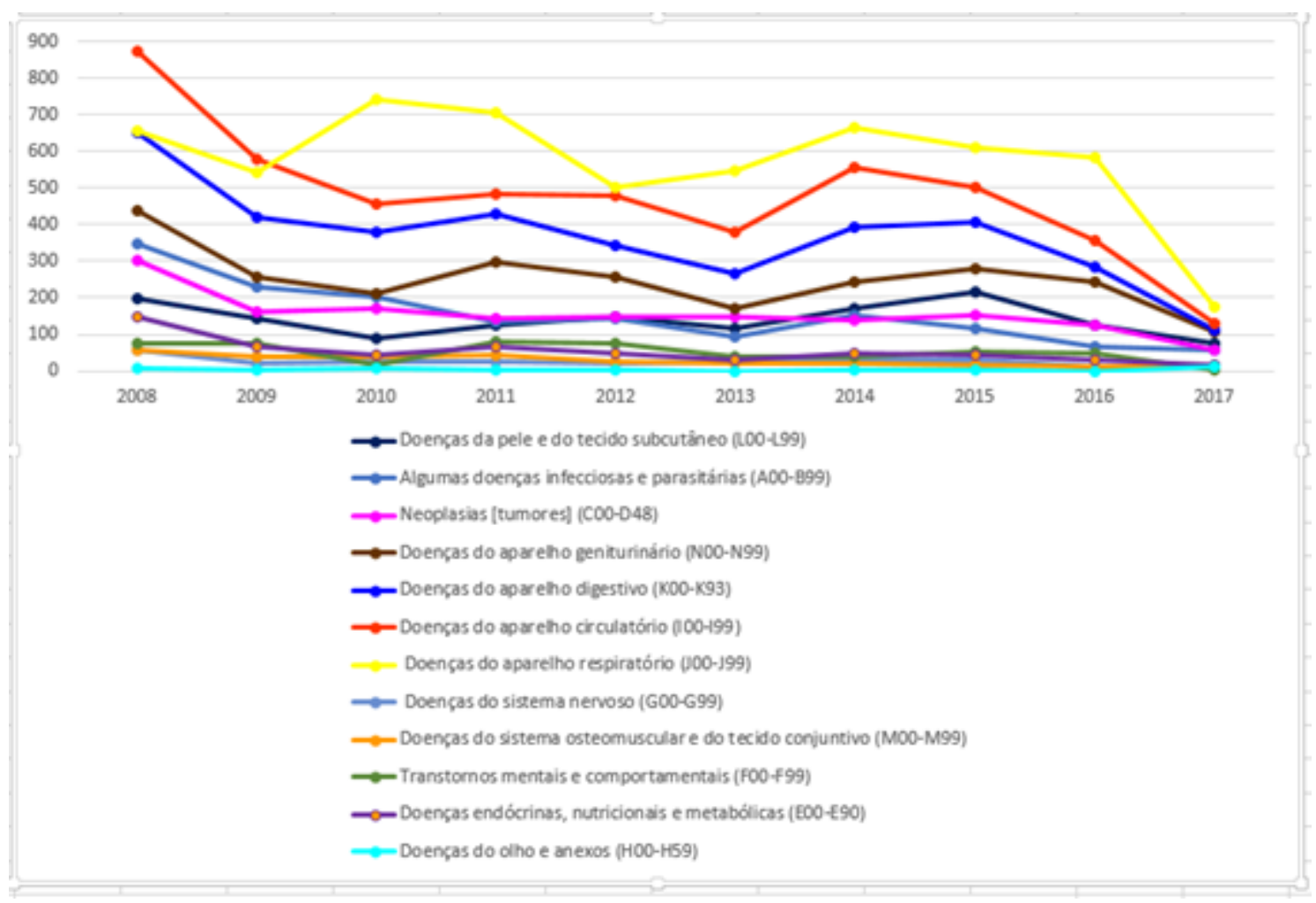

Obs.: Evolução das internações por grupo de doenças da CID 10 base nas categorias selecionadas.

Fonte dos dados: Brasil -MS/ DATASUS/ SIH/SUS/ TabWin (2018c).

Na Tabela 1, observa-se que dentre os problemas de saúde referidos pelos moradores pesquisados pelo menos três encontram-se mais visíveis, como o sistema respiratório pela alergia à poeira tóxica, na sequência o sistema circulatório pela hipertensão arterial sistêmica associada ao cianeto residual e depois as neoplasias denominadas de câncer sem tipologia definida relacionadas ao consumo de água poluída, efeitos atribuídos ao processo minerário presente no território. 
Tabela 1 - Problemas de Saúde referidos por moradores residentes próximos à mineradora em Paracatu (MG).

\begin{tabular}{|c|c|c|c|}
\hline Capitulo CID10 & Categoria & Respostas dos Entrevistados & Frequência \\
\hline$x$ & Doenças do aparelho respiratório & $\begin{array}{l}\text { Gripe e resfriado; Rinite; } \\
\text { Pneumonia; Bronquite; Alergia à } \\
\text { poeira; Sinusite; Asma; Problemas } \\
\text { respiratórios. }\end{array}$ & 99 \\
\hline IX & Doenças do aparelho circulatório & $\begin{array}{l}\text { Hipertensão; Pressão Alta; Doença } \\
\text { do coração; Trombose da veia; } \\
\text { Problema Vascular; Acidente } \\
\text { Vascular Cerebral nâo especificado. }\end{array}$ & 40 \\
\hline 11 & Neoplasias [tumores] & Câncer sem especificar tipo. & 32 \\
\hline$x \mid I I$ & $\begin{array}{c}\text { Doenças do sistema osteomuscular } \\
\text { e do tecido conjuntivo }\end{array}$ & $\begin{array}{l}\text { Artrite; Artrite reumatóide; Tendinite; } \\
\text { Problema na coluna; Lombalgia; } \\
\text { Hérnia de disco; Artrose. }\end{array}$ & 26 \\
\hline IV & $\begin{array}{c}\text { Doenças endócrinas, nutricionais e } \\
\text { metabólicas }\end{array}$ & $\begin{array}{l}\text { Diabetes; Tireóide; Obesidade; } \\
\text { Colesterol alto; Glaucoma. }\end{array}$ & 22 \\
\hline $\mathrm{V}$ & Doenças do sistema nervoso & $\begin{array}{l}\text { Cefaleia; Tontura e dor de cabeça; } \\
\text { Distúrbios neurológicos; Problema } \\
\text { neurológico (Disritmia). }\end{array}$ & 8 \\
\hline$x \|$ & $\begin{array}{c}\text { Doenças da pele e tecido } \\
\text { subcutâneo }\end{array}$ & Alergia da pele. & 8 \\
\hline$\vee$ & $\begin{array}{l}\text { Transtornos mentais e } \\
\text { comportamentais }\end{array}$ & $\begin{array}{l}\text { Alcoolismo; Depressão; Tabagismo; } \\
\text { Distúrbios mentais. }\end{array}$ & 5 \\
\hline XI & Doenças do aparelho digestivo & $\begin{array}{l}\text { Problema no estômago; Problema } \\
\text { no figado; Gastrite; Problema } \\
\text { gastrointestinal. }\end{array}$ & 4 \\
\hline XIV & Doenças do aparelho geniturinário & Problema nos rins. & 3 \\
\hline VII & Doenças do olho e anexos & Problema na Visão. & 3 \\
\hline 1 & $\begin{array}{c}\text { Algumas doenças infecciosas e } \\
\text { parasitárias }\end{array}$ & Hanseniase. & 1 \\
\hline
\end{tabular}

* CID-10: Classificação Internacional de Doenças e Problemas Relacionados à Saúde (Código Internacional de Doenças). Fonte: Pesquisa direta (2018;2019). Elaborado por: Astolphi (2019).

Para este estudo, optou-se por selecionar alguns tipos de neoplasias, como ilustrado na figura 7, através da sua relação com os efeitos da exposição prolongada do arsênio à saúde dos moradores de Paracatu. De acordo com Andrade e Rocha (2016) acerca do potencial cancerígeno de algumas espécies de arsênio:

Nos últimos anos, a ingestão do arsênio através da água, tem emergido como uma grande questão de saúde pública. $O$ arsênio contido em corpos d'água através de depósitos naturais ou por práticas agrícolas e industriais, principalmente pela mineração, vem causando consequentemente uma grande exposição humana, aumentando os riscos a cânceres e inúmeros efeitos patológicos, tais como: doenças cutâneas, gastrointestinais, vasculares, diabetes, já a exposição continuada a níveis baixos de arsénio inorgânico produz neuropatia periférica. Esta neuropatia começa, usualmente, com mudanças sensoriais, como falta de sensibilidade nas mãos e pés e desenvolve para uma sensação dolorosa. Os nervos motores e sensitivos podem ser afetados, levando a uma fraqueza muscular que progride dos músculos proximais para os distais. (ANDRADE; ROCHA, 2016, p. 3).

Quanto à internação hospitalar no grupo II neoplasias [tumores] apresentada na figura 7, elencamos as dezesseis causas de maior frequência e destas sete se relacionam aos órgãos bexiga, pele, pulmão, próstata e trato urinário. A análise da fig. 6, mostra o processo de evolução crescente de algumas neoplasias e período de ocorrência, como segue: neoplasia maligna de traqueia, brônquios e pulmões(crescimento nos anos 2012-13 mantido em 2014-15); outras neoplasias órgão respiratório, neoplasias maligna de pele e outras neoplasias malignas da pele (cresce de forma semelhante nos 
anos 2010-11); para as neoplasias maligna de próstata (aumento nos anos 2012-13) ; as neoplasias maligna da bexiga (crescimento nos anos 2014-15) e outras neoplasias malignas do trato urinário (crescimento nos anos 2008-9 e mantidos nos períodos 2010-11 e 2012-13).

Figura 7 - Internação hospitalar grupo II neoplasias [tumores] CID 10 por local de residência município Paracatu (MG) no período 2008-2017.

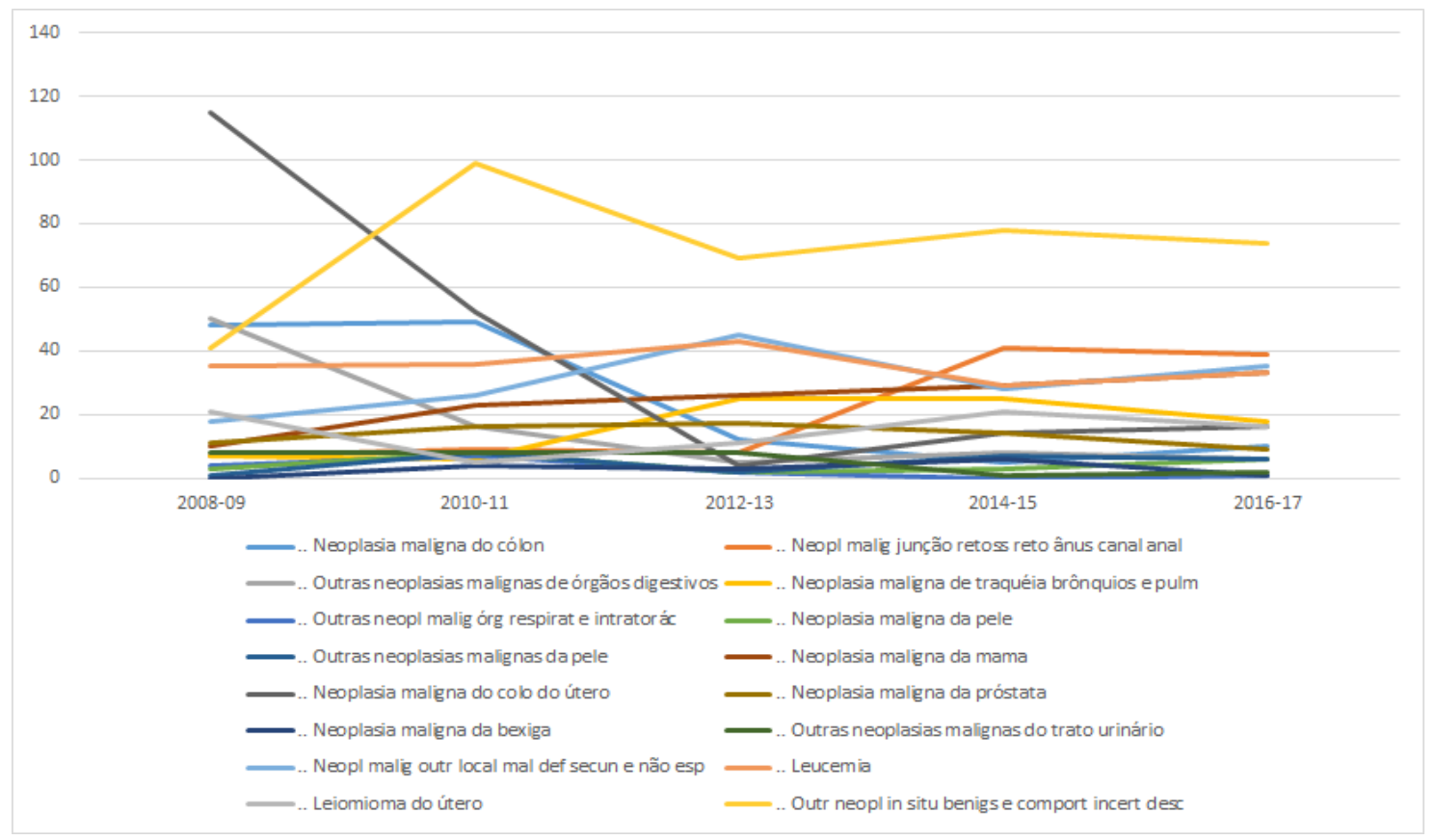

Fonte dos dados: Brasil -MS/ DATASUS/ SIH/SUS/ TabWin (2018d).

De acordo com a WORLD HEALTH ORGANIZATION (2001), em relação aos riscos do arsênio para a saúde humana:

Arsênio é um elemento pouco usual, no sentido de que existem dados epidemiológicos humanos de qualidade científica aceitável para a avaliação dos riscos à saúde associados à exposição de longo prazo ao arsênio, o qual tem uma relação causal com os riscos aumentados de câncer de pele, pulmão, bexiga e rins, bem como outras alterações da pele, como hiperceratose e alterações da pigmentação. Esses efeitos têm sido claramente demonstrados em um número de estudos epidemiológicos de diferentes desenhos. (WORLD HEALTH ORGANIZATION, 2001, p.136).

Um dos maiores problemas associados à produção do ouro no município de Paracatu é a consequente liberação do elemento arsênio no ar e nos corpos d'água. Representa um ametal com elevada toxicidade cujas consequências da sua ingestão estão associadas a disfunções cognitivas e formação de tumores (SALES, 2013). Também foi identificada a relação entre a exposição a longo prazo ao arsênio e a prevalência de hipertensão. (CHEN et al. 1995 apud WORLD HEALTH ORGANIZATION 2001).

Enfim, observa-se que há muito que fazer pela saúde e bem-estar de populações que vivem em locais onde há exploração comercial de bens naturais como o caso do ouro em Paracatu. As pessoas se veem diante de impasses como a falta de atenção à saúde ou, quando muito, uma atenção apenas do ponto de vista socorrista, ou seja, quando deveria se evitar a doença as atitudes tanto de empreendedores quanto do poder público, apontam para o fato de que "é mais fácil tratar do que evitar". A população do município, e da cidade como um todo, pede socorro. E deixamos como ponto de reflexão a seguinte questão: a quem cabe a responsabilidade pela saúde e bem-estar de moradores e trabalhadores expostos aos efeitos da exploração do ouro em Paracatu? 


\section{CONCLUSÃO}

A apropriação do espaço por um grande empreendimento, além da referida apropriação do território e das práticas de dominação econômica de uma empresa em uma dada região, pode trazer sérias consequências ao bem-estar de moradores expostos aos efeitos da atividade instalada. Também se observa uma produção de discursos de segurança em relação aos riscos e a qualidade ambiental, como os casos do ar e da água, com base em análises técnicas que ao invés de esclarecer os moradores da condição de risco a que estão submetidos, na verdade produz um desencontro de informações e, por isso, as consequências da atividade extrativista podem, muitas vezes, passarem despercebidas. No caso em apreço, muitos moradores têm clareza dessa submissão a riscos de toda ordem, porém, reclamam da falta de condições para deixarem suas casas e se mudarem para lugares mais seguros.

De fato, o contato dos pesquisadores com a realidade vivida por essa gente, revela contradições no discurso de segurança e como cada família faz para continuar a sobreviver diante de tantas ameaças ao seu modo de vida, à sua saúde e ao seu bem-estar. Desta forma, os discursos contrários são desqualificados e silenciados, numa relação desigual de poder. Esta situação se intensifica com o aumento da produção da empresa, o que representa um aumento proporcional da degradação ambiental e dos riscos à saúde da população.

Contudo, a percepção traduzida na fala contundente da população dos dois bairros contíguos à área de lavra da mineradora, realça a relação dos riscos à saúde e a condição de vulnerabilidade gerada pela exposição diária ao meio ambiente degradado, impostas no território pelo grande empreendimento minerário. Sair ou permanecer no lugar deixou de ser uma opção, contrariando a tese de que todos são livres para tomar as decisões mais convenientes. O medo de ficar desempregado e, com isso, a necessidade de garantir o sustento da família, faz com que a única "opção" seja a de permanecer no lugar, apesar dos diversos riscos à vida de tantas famílias.

Embora seja uma atividade econômica de grande importância na história e no desenvolvimento do município, a mineração é uma atividade que pode trazer diversos problemas à saúde e ao bem-estar das pessoas. Nas pesquisas desenvolvidas pelos autores foi possível perceber traços de relação entre a exposição do trabalhador e de moradores próximos à empresa e problemas de saúde que merecem maior atenção por parte do poder público.

\section{REFERÊNCIAS}

AMADO, G. Ouro roubado foi extraído em Minas Gerais e pertencia a mineradora canadense. ÉPOCA, Rio de Janeiro. 29 jul. 2019. Disponível em: https:/lepoca.globo.com/guilhermeamado/ouroroubado-foi-extraido-em-minas-gerais-pertencia-mineradora-canadense23839758. Acesso em: 30 jul. 2019

ANDRADE, D. F.; ROCHA, M. S. A Toxicidade do arsênio e sua natureza. Revista Oswaldo Cruz, ano 3, n.10, p.1-8, 2016.

BARROS, J. N. Mineração e violações de direitos: o caso da empresa Kinross em Paracatu (MG). Rio de Janeiro: Graffito Gráfica, 2017.

BIDONE, E. D., CESAR, R., SANTOS, M. C., SIERPE, R. V., SILVA-FILHO, E. V., KUTTER, V. T., SILVA, L. I. D., CASTILHOS, C. C. Mass balance of arsenic fluxes in rivers impacted by gold mining activities in Paracatu (Minas Gerais State, Brazil). Environmental Science and Pollution Research, v.25, n.9, p. 9085-9100, 2018. https://doi.org/10.1007/s11356-018-1215-z

BRASIL. Departamento Nacional de Produção Mineral - DNPM / Série Bússola Mineral (2008). Cooperativismo Mineral no Brasil: o caminho das pedras, passo a passo/ Ministério de Minas e Energia. Disponível em: www.dnpm.gov.br/...mineral/.../bussola-mineral-o-cooperativismo-mineral-nobrasil. Acesso em 02 out. 2018.

Ministério de Minas e Energia. Departamento Nacional de Produção Mineral - DNPM. Sumário Mineral. Brasília; 2018

Ministério das Minas e Energia. Departamento Nacional de Produção Mineral (DNPM). Compensação Financeira pela Exploração de Recursos Minerais (CFEM). Brasília, DF, 2018b.

Ministério da Saúde. Departamento de Informática do SUS (DATASUS). Sistema de 
Informações Hospitalares do SUS (SIH/SUS). TabWin. Brasília, DF, 2018c.

Ministério da Saúde. Departamento de Informática do SUS (DATASUS). Sistema de Informações Hospitalares do SUS (SIH/SUS). TabWin. Brasília, DF, 2018d.

BRITO, T. M. A importância das escalas espaciais para compreensão do processo de globalização. Geografias: Revista do Departamento de Geografia e do Programa de Pós-graduação em Geografia do IGC- UFMG, v.2, n.1, p. 93-106, jan./ jun. 2006.

CASTILHOS, Z. et. al. Avaliação Da Contaminação Ambiental Por Arsênio E Estudo Epidemiológico Da Exposição Humana Em Paracatu-MG - Brasil. Journal of Social, Technological and Environmental Science, v.9, n.1, p.9 186-211, 2020. https://doi.org/10.21664/22388869.2020v9i1.p186-211

CRAW, D., BOWELL R. J. The characterization of arsenic in mine waste. Reviews in Mineralogy \& Geochemistry. v.79, p.473-505, 2014. https://doi.org/10.2138/rmg.2014.79.10

CRUZ, J. Limite entre a área urbana de Paracatu e a Mina Morro do Ouro. Agência Brasil, 2015. Disponível em: http://agenciabrasil.ebc.com.br/tags/jose-cruzagencia-brasil. Acesso: em 20 de jun. 2018.

CUTTER, S. L. Vulnerability to environmental hazards. Progress in Human Geography, v. 20, n 4, p 529-539, 1996. https://doi.org/10.1177/030913259602000407

. Environmental risks and hazards. London: Prentice-Hall, 1994.

GIL, A. C. Métodos e técnicas de pesquisa social. São Paulo: Atlas, 1999.

GONÇALVES, J. A. C. (2011). A contaminação natural por arsênio em solos e águas subterrâneas na área urbana de Ouro Preto (MG). 2011. Dissertação (Mestrado em Evolução Crustal e Recursos Naturais). Universidade Federal de Ouro Preto, Ouro Preto.

IBRAM. Instituto Brasileiro de Mineração. Estatísticas\ Produção Mineral Brasileira. Disponível em: http://www.ibram.org.br/ Estatísticas/Produção Mineral Brasileira 2018/. Acesso: em 13 mai.2019.

KINROSS DO BRASIL. Conheça a Kinross. Notícia, 2020. Disponível em: http://www.kinross.com.br/. Acesso em: 09 de jan. 2020.

MARTINS, V. Desenvolvimento inequívoco deixa as suas mazelas no progresso. Correio Braziliense, Brasília, 31 de mai. 2010.2 Disponível em: http://www.correiobraziliense.com.br/app/noticia182/2010/05/31/economia,i=195280/DESENVOLVIME NTO+IINEQUIVOC+DEIXA . Acesso em: 11 set. 2017.

MELLO, J.W.V.; ROY, W. R; TALBOTT, J. L.; STUCKI, J. W. Mineralogy and arsenic mobility in arsenic-rich brazilian soils and sediments. JSS - J Soils \& Sediments, v.6, p. 9-19, 2006. https://doi.org/10.1065/iss2005.09.144

SALES, S. C. M. de. Avaliação ecotoxicológica de impactos da contaminação por metais e arsênio em áreas de mineração e beneficiamento de ouro em Minas Gerais. 2013. 157p. Tese de Doutorado. Universidade Federal de Minas Gerais, Brasília: DF, 2013.

SANTOS, M. J. dos. O Ouro e a Dialética Territorial em Paracatu: opulência e resistência. 2012. 193p. Dissertação de Mestrado - Universidade Católica de Brasília, Brasília: DF, 2012.

SANTOS, M. J. dos; ARAUJO, P. R. da R. Ameaças Ambientais de uma Mineração a Céu Aberto. IN: Encontro Nacional da ANPPAS, 2010. Florianópolis: SC. Disponível em: http://www.anppas. org.br/encontro5/cd/artigos/GT4-748-797-20100828130756.pdf. Acesso em: 11 set. de 2018.

SINCOVICH, A.; GREGORY, T.; WILSON, A.; BRINKMAN, S. The social impacts of mining on local communities in Australia. Rural Society, v.27, n.1, p.18-34, 2018. https://doi.org/10.1080/10371656.2018.1443725

SOUZA, E. S. As vozes das mulheres trabalhadoras rurais no assentamento Herbert de Souza Município de Paracatu/Mg - Aprendendo com as mulheres do campo. 2015. 174p. Tese de Doutorado- Universidade de Brasília. Faculdade de Educação. Programa de Pós-Graduação em Educação e Ecologia Humana, Brasília: DF, 2015. 
. A crise socioambiental das águas no município de Paracatu. Paracatu, 2014.

TUAN, Y. Paisagens do medo. São Paulo: UNESP, 2005.

Espaço e lugar: a perspectiva da experiência. São Paulo: DIFEL,1983

VELOSO, R. W. V.; MELLO, R. W. V. de; ABRAHÃO, W. A. P.; GLAUSAUERDI, S. Seasonal impacts on arsenic mobility and geochemistry in streams surrounding a gold mineralization area, Paracatu, Brazil. Applied Geochemistry, v.109, p.1-11, 2019. https://doi.org/10.1016/j.apgeochem.2019.104390

VEYRET, Y. Os riscos: o homem como agressor e vítima do meio ambiente. São Paulo: Contexto, 2015.

WORLD HEALTH ORGANIZATION - WHO (2001). United Nations Synthesis Report on Arsenic in Drinking-Water. Disponível em: http://www.who.int/water_sanitation_health/dwq/arsenic3/en/. Acesso em: 11 set. 2017. Acesso em: 13 mai. 2018. 